\title{
THE INFLUENCE OF SCHOOL CLOSURE IN THE CONTROL OF SPREAD OF INFECTIOUS DISEASE AMONG CHILDREN.
}

\author{
BY WILLIAM WRIGHT, M.D., D.P.H. (Camb.), \\ Senior Assistant Medical Officer of Health, Glasgow.
}

IT is chiefly in connection with the three diseases, diphtheria, scarlet fever, and measles, that school closure is ever contemplated, and in consequence I have deemed it necessary to discuss only those three.

If we take the cases of diphtheria occurring during the school holiday period, i.e., six weeks, and contrast them with the number occurring in corresponding periods before and after, it will bring into prominence the extent of the influence which the schools exercise on the prevalence of the disease. I quote the Glasgow figures for 1905. For those three periods the total number of cases of diphtheria notified was 207 , and these were distributed as follows:-

$\begin{array}{clllll}\text { During the } 1 \text { 1st or pre-holiday period } & & \ldots & 57 \\ , " \quad & \text { 2nd } " \text { ", period .. } & \ldots & 57 \\ & 207\end{array}$

Of these 93 cases notified in the third period, 24 were under three years of age, 57 , or 61 per cent, were between three and thirteen (i.e. school ages), while the remaining twelve cases were at ages beyond.

Again, taking the whole of the cases notified during the three periods, namely 207 :-

60 , or 29 per cent, were under three years of age,

116, , 56 per cent, , at school ages, while only

31 , , 15 per cent, ,, at ages beyond.

These figures go towards showing that the segregation of large numbers of children of susceptible ages in schools is in favour of its dissemination; and when one recognizes that it can be propagated only through the breath or saliva this ought to be generally accepted.

\section{Example.}

On the occurrence of two cases of diphtheria in one class-room in a school in the northern district of the city, quite recently, I examined all the children, and was successful in isolating two definite cases and five suspicious ones; the first two being sent to hospital, and the others home. Two of the latter on bacteriological examination proved positive, and were similarly dealt with, the remaining three 
being kept at home until better. The slates and sponges were steeped in lysol over the week-end, and such rags as the scholars had for drying their slates, with all their pencils, were burned the same day. No other cases occurred. Scribbling blocks are preferable to slates, and should be in use in all schools.

If we examine scarlet fever in the same manner, we shall find what at first sight would appear to be similar results, but their interpretation is different. During the three periods there were 300 cases notified, distributed as follows :-

1. During the pre-holiday period, 85 cases, or 28 per cent)

2. " , holiday period, 69 cases, or 23 per cent 300

3. " post-holiday period, 146 cases, or 49 per cent

It will be seen that almost twice the number of cases occurred during the post-holiday period than during the pre-holiday period. Although this would appear to condemn the school, it is to be remembered that the increase in the seasonal incidence of scarlet fever is coincident with the commencement of the post-holiday period, the average weekly figures for the twelve years 1893-1904 being as follws :-

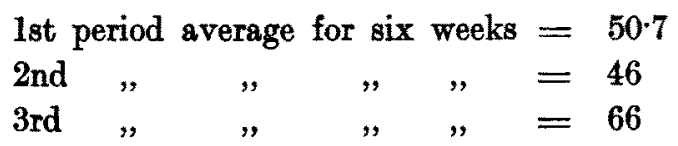

rising to its highest point in the third week in October, i.e., 93.

I think it will generally be agreed that the school exerts but little influence in the spread of scarlet fever. The experience in Glasgow has been that, except from the occasional occurrence of limited groups of cases due to class infection, no epidemic has resulted from contact at school.

\section{Examples.}

1st April to 11th May, 1901, 5 cases, one classroom, ceased thereafter. 26th Sept. to 10th Oct., 1901, 5 cases, one classroom, cessed thereafter. 10th Jan. to 28th Jan., 1904, 5 cases, one classroom, ceased thereafter. 21st April to 8th May, 1903, 9 cases, one classroom, ceased thereafter.

The problem of the control of measles by school closure is the one with which we are most familiar. The question of the utility of attempting to control it by this means is best approached by reviewing the characteristics of the disease itself. These are :-

1. High infectivity in the early stages of the disease before it is recognized.

2. Its virulence. 
3. Liability to recur in epidemic form two years in succession in the same district, the second being more virulent than the first.

4. Liability to a recrudescence in the third year in the same district, and in a form so severe that the case-rate incidence will be greater than that of the city as a whole.

As an illustration, I quote the figures for Glasgow for the years 1903, 1904, and 1905 :-

In Springburn Ward measles formed 51 per cent of all infectious diseases in 1903 , in 190498 per cent, and in 190566 per cent. The percentage for the whole city was 63 per cent in 1905 .

In Anderston Ward measles formed 31 per cent of all infectious diseases in 1903, in 190459 per cent, and in 190567 per cent. Here the proportion of measles in the third year was greater than that of the city by 4 per cent.

The theory has been advanced that, since the age-incidence of the disease is known to be 1-6 years, if we can prevent the child from coming into contact with the disease during that period it will then enter into a period of comparative immunity. In other words, if we succeed in altering the age-incidence of the disease from that critical period, 1-6, we shall thereby diminish its case-incidence. If this theory held good in practice, then it would follow that children brought up in the country, or in small villages where the population is sparse, and where they are comparatively free from measles or other epidemic diseases, ought to be practically immune from attack when exposed to infection in adult life. That this is not the case $I$ shall proceed to show. In Belvidere Fever Hospital Report for 1904 I find that almost the whole of the adult patients treated for measles had come from remote and sparsely populated districts, and had not been exposed to infection in childhood. The actual figures are as follows:-

The number of cases occurring between 15 and 45 years of age was 75 ; and of these 67 , or 89 per cent, were born in the country. This clearly demonstrates the continued susceptibility of persons who have not already had the disease. I may refer also to the outbreak of measles which occurred in the Volunteer Camp at Fort George last year, I think. The saving point in the argument is that the recuperative forces are greater in the adult than in the child; and this is reflected in the case-mortality, which is overwhelmingly in favour of the adult. The highest case-mortality is 0-2 years. Again, it may be contended that by raising the compulsory age-limit from 5 to 6 years all or most of the children shall already have suffered from the disease before attendance at school. If all have been attacked. 
then it is obvious that the school can no longer spread infection, and Public Health administration has achieved nothing, but school attendance shall go on uninterrupted, and the measure consequently shall be of great educational value. If most have been attacked, then the remainder (very few indeed, I think), as far as school influence is concerned, are just as they were, ready for attack, but with this difference, that they form members of a class who have all suffered from measles: the possibility of direct infection has been removed, but that of indirect still exists.

It is held by some that school closure is efficacious in the control of measles. In several districts, where the home conditions are all that could be desired, this may be the case; but in large populous centres, such as Glasgow, where slum dwellings exist, and rows and rows of tenements where large numbers of children are gathered together playing in and out of each other's houses, in alleys and courts, such highly desired results are not to be expected.

As regards large centres, it must not be forgotten that if schools were to be closed whenever infectious disease was prevalent, there are many places where schools would never be open.

\section{Remedy.}

1. The regular medical inspection of schools, with the view of picking out the earliest cases, is infinitely better and more capable of carrying into effect than the closure of the school on the recognition of the first case (more theoretical than practical), or the indiscriminate closure of schools after the attendance has fallen 30 to 40 per cent. This, combined with the swabbing of the throats in the case of diphtheria, and the free distribution of antitoxin as a prophylactic in infected households.

2. The education of the mothers of the lower working classes in their responsibility to their children towards uprooting the oldestablished idea of so lightly regarding measles as a disease, its infection and spread ; warning them of its extreme virulence and complications. This might be embodied in a circular for distribution similar to that in use in Glasgow since 1897, and examples made in all instances where carelessness has been exhibited in the spread of infection. I quote a case in point, where a drunken, careless mother, carrying her infant, which was suffering from measles, was proven to have infected fifteen different households, and, when severely reprimanded, pleaded ignorance of the nature of the child's illness. Doubtless many other instances of the kind can be recorded. 